\title{
Comparative Analysis of the Circle Fitting Empirical Method and the International Telecommunication Union Parabola Fitting Method for Determination of the Radius of Curvature for Rounded Edge Diffraction Obstruction
}

\author{
Simeon Ozuomba \\ Department of \\ Electrical/Electronic and \\ Computer Engineering University \\ of Uyo \\ Akwa Ibom State Nigeria
}

\author{
Constant Kalu \\ Department of \\ Electrical/Electronic and \\ Computer Engineering University \\ of Uyo \\ Akwa Ibom State Nigeri.
}

\author{
Henry Johnson Enyenihi \\ Department of \\ Electrical/Electronic Engineering, \\ Akwa Ibom State University \\ Mkpat Enin, \\ Akwa Ibom State Nigeria
}

\begin{abstract}
In this paper, comparative analysis of the circle fitting empirical method and the parabola fitting method for determination of the radius of curvature for rounded edge diffraction obstruction was presented. Sample elevation profile data for a $40 \mathrm{Km}$ path with hilly obstruction was collected using web-based Geocontext elevation profile tool. The maximum elevation of $307.4569 \mathrm{~m}$ occurred at a distance of $35966.33 \mathrm{~m}$ the maximum elevation point from the transmitter. The two radius of curvature methods were applied to the elevation data. The exact radius of curvature based on the circle fitting empirical method is $38,375.22 \mathrm{~m}$ whereas the radius of curvature based on the International Telecommunication Union (ITU) parabola fitting method is $34,029.98 \mathrm{~m}$. Furthermore, while the radius by the empirical circle fitting method remained the same under different microwave frequencies, for the ITU parabola fitting method, there was over $89 \%$ reduction in the radius of curvature from $60,369.69 \mathrm{~m}$ at $1 \mathrm{GHz} \mathrm{L}$-band microwave frequency to $11,476.36 \mathrm{~m}$ at $12 \mathrm{GHz}$ Ku-band microwave frequency. The essence of this study is to demonstrate the wide variation in the radius of curvature due to the frequency and also to advise that the ITU method may be used only when the ITU method of rounded edge diffraction loss is employed. The other rounded edge diffraction loss methods can use other approximation methods that compare favorably with the exact radius in all frequencies.
\end{abstract}

\section{Keywords}

Diffraction loss, rounded obstruction, parabola fitting method, radius of curvature, wireless communication.

\section{INTRODUCTION}

Nowadays, there is wide adoption of wireless communication across the globe $[1,2,3,4]$. As the adoption of wireless communication increases, experts are facing running challenges in providing adequate quality of service to the teeming population of wireless communication network users. One of the challenges in wireless communication is the diffraction loss due to obstructions in the path of the wireless signal $[5,6,7,8,9,10]$. Obstructions like mountains and trees are in some cases modeled as knife-edge obstructions $[11,12,13,14,15,16,17,18]$. However, further studies revealed that single knife-edge model of such obstruction usually underestimate the actual diffraction loss posed by obstructions like hills. In respect of this finding, for hilly obstructions , rounded edge obstruction model is usually used instead of the knife-edge model $[19,20,21]$.

Generally, in the rounded edge obstruction model, a curve is fitted to the vicinity of the hill apex. The radius of curvature of such curve along with angles made by tangent lines to the curve is then used in the computation of the rounded edge diffraction loss. One of the popular methods of generating the curve is by fitting a circle to the vicinity of the hill apex. However, the International Telecommunication Union (ITU) developed a parabolic curve fitting reproach for the rounded edge diffraction loss computation [22]. Remarkably, based on the underlying formula and constraint presented by ITU, the radius of the parabolic curvature is affected by the frequency of the signal. In this paper, comparative study of the ITU parabola fitting method and the circle fitting method for determination of the radius of curvature of rounded edge obstruction is presented. Specifically, for the circle fitting method, the exact radius of curvature is obtained using empirical measurements conducted on the path elevation profile plot of the hilly obstruction along the signal path. The study is meant to show the disparity in the values of the radius of curvature obtained using the two methods and how the values vary with respect to the frequency.

\section{THE RADIUS OF CURVATURE BY THE ITU PARABOLA FITTING METHOD}

Unlike the other approximate method that tends to use radius of circle to determine the radius of curvature for rounded edge diffraction loss computation, the International Telecommunication Union (ITU) uses a parabolic fitting approach whereby a parabola is fitted to the vicinity of the obstruction apex. The ITU approach requires that the maximum vertical distance from the apex of the obstruction should be about the same as the radius of the first Fresnel zone computed at the point where the obstruction apex is located. The parabola along with the parameters used for the ITU parabola fitting method is shown in Figure 1 ' 


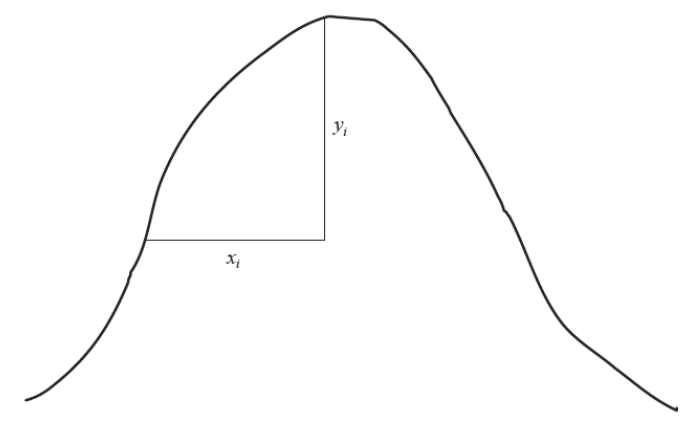

Figure 1 The parabola along with the parameters used for the ITU parabola fitting method

First, the radius of the first Fresnel zone at the apex of the obstruction is computed as follows [23];

$$
R_{f 1}=17.32\left(\sqrt{\frac{\left(d_{t a}\right)\left(d_{r a}\right)}{f\left(d_{t} a+d_{r a}\right)}}\right)
$$

Where $\mathrm{f}$ is frequency in $\mathrm{GHz}$ and $\mathrm{d}_{\mathrm{ta}}$ in $\mathrm{Km}$ is the distance of the obstruction apex from the transmitter while $\mathrm{d}_{\mathrm{ra}}$ in $\mathrm{Km}$ is the distance of the obstruction apex from the receiver.

Then, based on Figure 1 and the ITU parabolic fitting approach, if $E_{a}$ is the elevation of the obstruction apex, then all elevation data points with elevation $E_{i}$ such that $E_{a}-E_{i} \leq$ $R_{f 1}$ are used in the computation of the parabola parameter. Now, if the coordinates of the obstruction apex is given as $d_{a}, E_{a}$ and there are $\mathrm{Na}$ elevation data points that satisfy the condition that $E_{a}-E_{i} \leq R_{f 1}$, then the radius of curvature, $r_{i}$ of the parabola at elevation point $i$ with distance and elevation coordinates given as $d_{i}, E_{i}$ is computed as follows [22] ;

$$
\begin{array}{lr}
\quad \mathrm{x}_{i}=d_{a}-d_{i} & \text { for } \mathrm{i}=1,2,3, \ldots, \mathrm{Na} \\
\mathrm{y}_{i}=E_{a}-E_{i} & \text { for } \mathrm{i}=1,2,3, \ldots, \mathrm{Na} \\
\mathrm{r}_{\mathrm{i}}=\frac{\mathrm{x}_{i}{ }^{2}}{2\left(\mathrm{Y}_{i}\right)} & \text { for } \mathrm{i}=1,2,3, \ldots, \mathrm{Na}
\end{array}
$$

Eventually, the median radius of curvature of the obstacle is given by [22]:

$$
\mathrm{R}=\frac{1}{N a}\left[\sum_{i=1}^{i=n}\left(\frac{\mathrm{x}_{i}{ }^{2}}{2 \mathrm{Y}_{i}}\right)\right]
$$

\section{THE EMPIRICAL METHOD FOR COMPUTING THE EXACT RADIUS OF CURVATURE FOR ROUNDED EDGE DIFFRACTION OBSTRUCTION}

Unlike the ITU method that fits in a parabola to the vicinity of the apex of the hilly obstruction, the exact method fits in a circle, as shown in Figure 2. So, the focus of the exact method is to determine the radius of the circle.

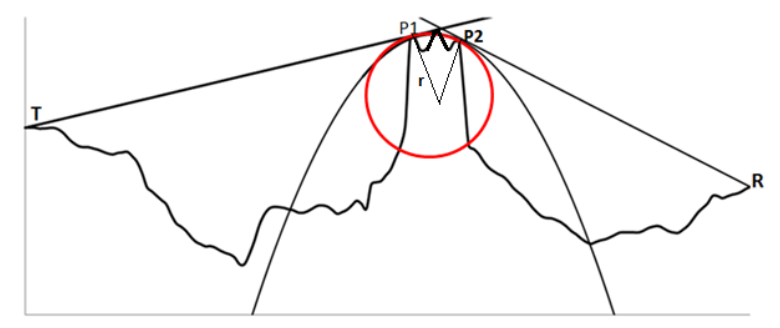

Figure 2 The path profile of the Hilly obstruction along with the sketch of the circle to be fitted by the exact method and the parabola to be fitted by the ITU method

In order to determine the radius of the circle, first, a tangent line $\mathrm{TP}_{1}$ is drawn from the transmitter, $\mathrm{T}$ to the path profile, which in this case is tangential at point $P_{1}$ A tangent line $R P_{2}$ is drawn from the receiver, $\mathrm{R}$ to the path profile, which in this case is tangential at point $P_{2}$. Line $T_{1}$ and line $R P_{2}$ are extended to intersect at $\mathrm{V}$, as shown in Figure 3. A line perpendicular to line $\mathrm{TP}_{1}$ is drawn at point $\mathrm{P}_{1}$. Another line perpendicular to line $\mathrm{RP}_{2}$ is drawn at point $\mathrm{P} 3$. The intersection of the two perpendicular line at point $\mathrm{C}$ gives the center of the circle. The line $\mathrm{CP} 1$ is the radius of the circle and it can be measured using a ruler. A protractor can be used to measure the relevant angles namely, $\beta 1, \beta 2$ and $\alpha$. Also, the clearance height, $h$ can also be measured using a ruler. Other lines that their lengths are needed to be measured are line TP1, RP1, the occultation distance P1P2 or line FG which is the horizontal distance between point P1 and point $\mathrm{P} 2$; line $\mathrm{BR}$ which is the path length or the distance between the transmitter and the receiver. Line BT which is the difference in the elevation between the transmitter and the receiver. 


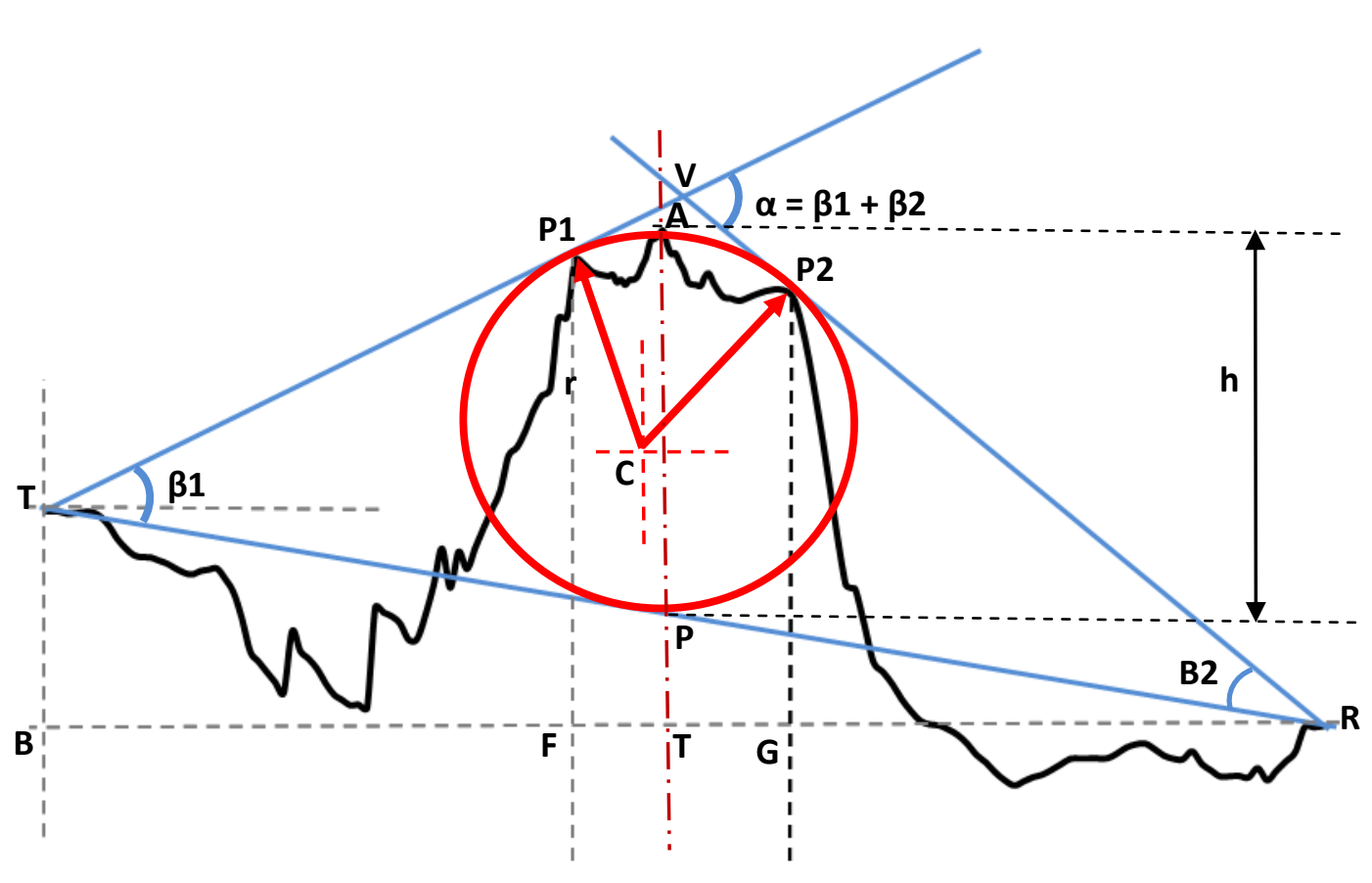

Figure 3 The detail path profile and parameters used in the exact method

\section{RESULTS AND DISCUSSIONS}

Sample elevation profile data was obtained using the Geocontext elevation profile web application. The elevation profile data obtained for a path with the hilly obstruction is given in Table 1 and Figure 4 .

In Table 2, the maximum elevation is 307.4569 , the distance of the maximum elevation point from the transmitter, $\mathrm{d}_{\mathrm{ta}}=35966.33 \mathrm{~m}$, the distance of the maximum elevation point from the receiver, $\mathrm{d}_{\mathrm{ra}}=4033.66847 \mathrm{~m}$, the frequency is $4 \mathrm{GHz}$, so the radius of the first Fresnel zone at the maximum elevation point is $16.49248 \mathrm{~m}$. As such in
Table 2 , all the that are used to determine the parabola curvature must be such that their $\mathrm{y}_{\mathrm{i}}$ are less than 16.49248 . That is what is shown in Table 2 , all the $y_{i} \leq 16.49248$. In all, there are 44 elevation points that satisfied the condition and the sum of $\left(\frac{\mathrm{x}_{\mathrm{i}}{ }^{2}}{2\left(\mathrm{y}_{\mathrm{i}}\right)}\right)$ obtained from that 44 points is $1497319.3 \mathrm{~m}$, so the parabola curvature radius is $1497319.3 / 44=34,029.98 \mathrm{~m}$. However, the exact radius obtained from the empirical measurement based on the elevation profile data is $38,375.22 \mathrm{~m}$.

Table 1 The elevation profile data of the path with the hilly obstruction

\begin{tabular}{|r|r|r|r|r|r|r|r|r|r|}
\hline \multicolumn{2}{|c|}{ Data points 1 to 30 } & \multicolumn{2}{c|}{ Data points 31 to 60 } & \multicolumn{2}{c|}{ Data points 61 to 90 } & \multicolumn{2}{|c|}{ Data points 91 to 120 } & \multicolumn{2}{|c|}{ Data points 121 to 150 } \\
\hline $\begin{array}{c}\text { Distance } \\
(\mathrm{m})\end{array}$ & $\begin{array}{c}\text { Elevation } \\
(\mathrm{m})\end{array}$ & $\begin{array}{c}\text { Distance } \\
(\mathrm{m})\end{array}$ & $\begin{array}{c}\text { Elevation } \\
(\mathrm{m})\end{array}$ & $\begin{array}{c}\text { Distance } \\
(\mathrm{m})\end{array}$ & $\begin{array}{c}\text { Elevation } \\
(\mathrm{m})\end{array}$ & $\begin{array}{c}\text { Distance } \\
(\mathrm{m})\end{array}$ & $\begin{array}{c}\text { Elevation } \\
(\mathrm{m})\end{array}$ & $\begin{array}{c}\text { Distance } \\
(\mathrm{m})\end{array}$ & $\begin{array}{c}\text { Elevation } \\
(\mathrm{m})\end{array}$ \\
\hline 0.0 & 233.2 & 18502.1 & 255.1 & 35282.2 & 299.0 & 36565.0 & 297.4 & 38114.7 & 250.9 \\
\hline 616.7 & 232.7 & 19118.8 & 255.4 & 35324.9 & 298.0 & 36607.7 & 297.8 & 38179.8 & 248.9 \\
\hline 1233.5 & 232.5 & 19735.5 & 255.6 & 35367.7 & 297.7 & 36650.5 & 298.5 & 38244.8 & 245.8 \\
\hline 1850.2 & 232.0 & 20352.3 & 255.9 & 35410.5 & 297.6 & 36693.2 & 295.5 & 38309.8 & 242.1 \\
\hline 2466.9 & 231.4 & 20969.0 & 256.4 & 35453.2 & 298.4 & 36736.0 & 295.0 & 38374.8 & 229.9 \\
\hline 3083.7 & 231.4 & 21585.7 & 257.0 & 35496.0 & 299.3 & 36778.8 & 293.9 & 38439.8 & 227.4 \\
\hline 3700.4 & 231.4 & 22202.5 & 257.7 & 35538.7 & 300.2 & 36821.5 & 292.6 & 38504.8 & 225.9 \\
\hline 4317.1 & 232.7 & 22819.2 & 258.7 & 35581.5 & 301.0 & 36864.3 & 291.2 & 38569.8 & 226.1 \\
\hline 4933.9 & 233.5 & 23435.9 & 259.8 & 35624.3 & 301.7 & 36907.0 & 290.1 & 38634.8 & 225.0 \\
\hline
\end{tabular}


Communications on Applied Electronics (CAE) - ISSN : 2394-4714

Foundation of Computer Science FCS, New York, USA

Volume 7-No. 24, December 2018-www.caeaccess.org

\begin{tabular}{|c|c|c|c|c|c|c|c|c|c|}
\hline 5550.6 & 234.3 & 24052.7 & 261.4 & 35667.0 & 302.3 & 36949.8 & 289.3 & 38699.8 & 224.5 \\
\hline 6167.4 & 235.1 & 24669.4 & 262.6 & 35709.8 & 302.6 & 36992.6 & 288.3 & 38764.8 & 215.3 \\
\hline 6784.1 & 235.7 & 25286.1 & 262.8 & 35752.5 & 301.6 & 37035.3 & 287.3 & 38829.8 & 210.7 \\
\hline 7400.8 & 236.3 & 25902.9 & 263.3 & 35795.3 & 301.9 & 37078.1 & 289.4 & 38894.9 & 209.6 \\
\hline 8017.6 & 236.9 & 26519.6 & 264.2 & 35838.1 & 304.7 & 37120.8 & 288.0 & 38959.9 & 208.3 \\
\hline 8634.3 & 237.7 & 27136.3 & 265.6 & 35880.8 & 304.7 & 37163.6 & 289.9 & 39024.9 & 206.8 \\
\hline 9251.0 & 238.3 & 27753.1 & 267.2 & 35923.6 & 306.5 & 37206.4 & 288.8 & 39089.9 & 190.4 \\
\hline 9867.8 & 238.8 & 28369.8 & 268.8 & 35966.3 & 307.5 & 37249.1 & 285.8 & 39154.9 & 186.6 \\
\hline 10484.5 & 239.8 & 28986.5 & 270.4 & 36009.1 & 306.3 & 37291.9 & 285.6 & 39219.9 & 183.3 \\
\hline 11101.2 & 240.9 & 29603.3 & 272.3 & 36051.9 & 305.1 & 37334.6 & 285.7 & 39284.9 & 184.0 \\
\hline 11718.0 & 242.4 & 30220.0 & 274.7 & 36094.6 & 304.2 & 37399.7 & 282.2 & 39349.9 & 181.1 \\
\hline 12334.7 & 243.8 & 30836.8 & 277.8 & 36137.4 & 303.5 & 37464.7 & 281.7 & 39414.9 & 178.4 \\
\hline 12951.4 & 245.4 & 31453.5 & 280.9 & 36180.1 & 303.0 & 37529.7 & 267.3 & 39479.9 & 180.4 \\
\hline 13568.2 & 246.7 & 32070.2 & 290.6 & 36222.9 & 302.5 & 37594.7 & 264.7 & 39544.9 & 180.4 \\
\hline 14184.9 & 247.5 & 32687.0 & 293.0 & 36265.7 & 302.1 & 37659.7 & 262.6 & 39609.9 & 181.7 \\
\hline 14801.6 & 248.3 & 33303.7 & 294.9 & 36308.4 & 301.6 & 37724.7 & 260.4 & 39675.0 & 182.5 \\
\hline 15418.4 & 249.1 & 33920.4 & 296.1 & 36351.2 & 301.1 & 37789.7 & 258.1 & 39740.0 & 183.2 \\
\hline 16035.1 & 250.3 & 34537.2 & 297.3 & 36393.9 & 297.0 & 37854.7 & 256.0 & 39805.0 & 186.9 \\
\hline 16651.8 & 251.7 & 35153.9 & 298.4 & 36436.7 & 296.9 & 37919.7 & 254.5 & 39870.0 & 185.6 \\
\hline 17268.6 & 253.3 & 35196.7 & 299.4 & 36479.4 & 296.8 & 37984.7 & 253.1 & 39935.0 & 186.4 \\
\hline 17885.3 & 254.6 & 35239.4 & 299.4 & 36522.2 & 297.1 & 38049.7 & 251.8 & 40000.0 & 187.9 \\
\hline
\end{tabular}

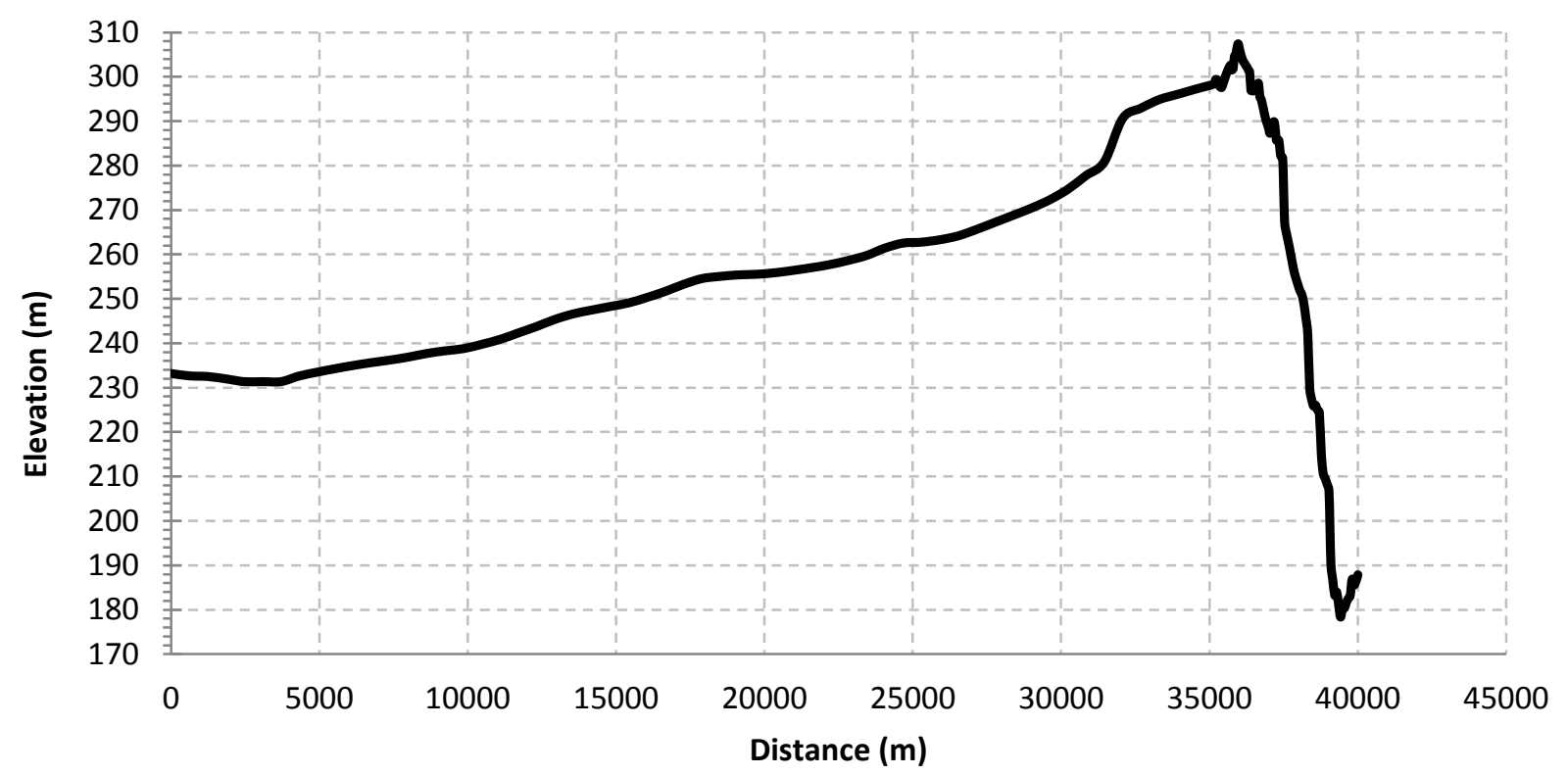

Figure 4 The elevation profile data plot for the path with the hilly obstruction 
Table 2 The Portion of the elevation data points that were used in the ITU parabola fitting approach at the Frequency of 4 GHz and path length of $40 \mathrm{Km}$

\begin{tabular}{|c|c|c|c|c|c|c|c|c|c|}
\hline $\begin{array}{c}\mathbf{S} / \mathbf{N} \\
\mathbf{i}\end{array}$ & $\begin{array}{c}\text { Elevation } \\
\text { Data } \\
\text { Point } \\
\text { Number }\end{array}$ & $x_{\mathbf{i}}$ & $\mathbf{y}_{\mathbf{i}}$ & $\frac{x_{i}{ }^{2}}{2\left(y_{i}\right)}$ & $\mathbf{S} / \mathbf{N}$ & $\begin{array}{c}\text { Elevation } \\
\text { Data } \\
\text { Point } \\
\text { Number }\end{array}$ & $x_{\mathbf{i}}$ & $\mathbf{y}_{\mathbf{i}}$ & $\frac{x_{i}{ }^{2}}{2\left(y_{i}\right)}$ \\
\hline 1 & 53 & 3,279 & 14.5 & 370,773 & 23 & 75 & 43 & 0.9 & 970 \\
\hline 2 & 54 & 2,663 & 12.6 & 281,975 & 24 & 76 & 43 & 1.2 & 763 \\
\hline 3 & 55 & 2,046 & 11.4 & 183,809 & 25 & 77 & 86 & 2.3 & 1,563 \\
\hline 4 & 56 & 1,429 & 10.2 & 100,076 & 26 & 78 & 128 & 3.3 & 2,522 \\
\hline 5 & 57 & 812 & 9.0 & 36,549 & 27 & 79 & 171 & 4.0 & 3,680 \\
\hline 6 & 58 & 770 & 8.1 & 36,567 & 28 & 80 & 214 & 4.4 & 5,184 \\
\hline 7 & 59 & 727 & 8.0 & 32,852 & 29 & 81 & 257 & 4.9 & 6,700 \\
\hline 8 & 60 & 684 & 8.5 & 27,625 & 30 & 82 & 299.3 & 5.3 & 8420.2 \\
\hline 9 & 61 & 641 & 9.4 & 21,856 & 31 & 83 & 342.1 & 5.9 & 9906.5 \\
\hline 10 & 62 & 599 & 9.8 & 18,338 & 32 & 84 & 384.8 & 6.3 & 11679.7 \\
\hline 11 & 63 & 556 & 9.8 & 15,717 & 33 & 85 & 427.6 & 10.5 & 8714.4 \\
\hline 12 & 64 & 513 & 9.0 & 14,605 & 34 & 86 & 470.4 & 10.6 & 10437.2 \\
\hline 13 & 65 & 470 & 8.2 & 13,497 & 35 & 87 & 513.1 & 10.6 & 12393.5 \\
\hline 14 & 66 & 428 & 7.3 & 12,537 & 36 & 88 & 555.9 & 10.4 & 14846.1 \\
\hline 15 & 67 & 385 & 6.5 & 11,391 & 37 & 89 & 598.6 & 10.0 & 17838.0 \\
\hline 16 & 68 & 342 & 5.8 & 10,089 & 38 & 90 & 641.4 & 9.6 & 21396.1 \\
\hline 17 & 69 & 299 & 5.2 & 8,612 & 39 & 91 & 684.2 & 9.0 & 26148.0 \\
\hline 18 & 70 & 257 & 4.8 & 6,790 & 40 & 92 & 726.9 & 11.9 & 22179.1 \\
\hline 19 & 71 & 214 & 5.9 & 3,879 & 41 & 93 & 769.7 & 12.5 & 23784.4 \\
\hline 20 & 72 & 171 & 5.6 & 2,617 & 42 & 94 & 812.4 & 13.6 & 24280.3 \\
\hline 21 & 73 & 128 & 2.8 & 2,991 & 43 & 95 & 855.2 & 14.9 & 24560.2 \\
\hline 22 & 74 & 86 & 2.7 & 1,344 & 44 & 96 & 898.0 & 16.2 & 24863.7 \\
\hline & & & & & & & & SUM & 1497319.3 \\
\hline
\end{tabular}

For the given elevation profile data, the radius of the rounded edge fitted in the vicinity of the hilly obstruction apex was determined for a number of frequencies and the results are given in Table 3 . The results show that the radius of curvature by the ITU method is significantly affected by the frequency. There was over $89 \%$ reduction in the radius of curvature from $60,369.69 \mathrm{~m}$ at $1 \mathrm{GHz}$ L-band microwave frequency to $11,476.36 \mathrm{~m}$ at $12 \mathrm{GHz} \mathrm{Ku}$-band microwave frequency. On the other hand, the exact radius by circle fitting empirical method did not change with the frequency. The essence of this study is to demonstrate this wide variation in the radius of curvature due to the frequency and also to advise that the ITU method may be used only when the ITU method of rounded edge diffraction loss is employed. The other rounded edge diffraction loss methods can use other approximation methods that compare favorably with the exact radius in all the frequencies.

Table 3 The radius of the rounded edge fitted in the vicinity of the hilly obstruction apex for different frequencies

\begin{tabular}{|c|c|c|c|c|c|}
\hline $\begin{array}{c}\text { Microwave } \\
\text { Frequency } \\
\text { Band }\end{array}$ & $\begin{array}{c}\text { Frequency } \\
\text { (GHz) }\end{array}$ & $\begin{array}{c}\text { Radius of } \\
\text { the first } \\
\text { Fresnel zone } \\
\text { (m) }\end{array}$ & $\begin{array}{c}\text { Number of elevation } \\
\text { data points used in } \\
\text { the ITU Parabola } \\
\text { Fitting Method }\end{array}$ & $\begin{array}{c}\text { Radius of curvature by } \\
\text { ITU Parabola Fitting } \\
\text { Method (m) }\end{array}$ & $\begin{array}{c}\text { Radius of curvature by } \\
\text { Empirical Circle Fitting } \\
\text { Exact Radius Method } \\
\text { (m) }\end{array}$ \\
\hline L-Band & 1 & 32.98496781 & 62 & $60,369.69$ & $38,375.22$ \\
\hline L-Band & 2 & 23.32389 & 57 & $40,848.07$ & $38,375.22$ \\
\hline C-Band & 4 & 16.49248 & 44 & $34,029.98$ & $38,375.22$ \\
\hline
\end{tabular}




\begin{tabular}{|c|c|c|c|c|c|}
\hline C-Band & 6 & 13.46606 & 41 & $25,679.07$ & $38,375.22$ \\
\hline Ku-Band & 12 & 9.52194 & 28 & $11,476.36$ & $38,375.22$ \\
\hline
\end{tabular}

\section{CONCLUSION}

The radius of curvature for rounded edge diffraction loss computation is determined using two different methods are presented. The methods are, one, the circle fitting empirical method which gives the exact radius for the circle and two, the International Telecommunication Union (ITU) parabola fitting method which fits a parabola to the vicinity of the obstruction apex. Requisite analytical expressions for the two methods are presented. A sample elevation profile data for the path with the hilly obstruction was collected and used to examine the effect of the frequency on the radius of curvature obtained using each of the two methods. The exact radius of curvature based on the circle fitting empirical method maintained the same value of the radius of curvature under different microwave frequencies. However, the ITU parabola fitting method gave over $89 \%$ reduction in the radius of curvature when the frequency was varied from $1 \mathrm{GHz} \mathrm{L}$-band microwave frequency to $12 \mathrm{GHz} \mathrm{Ku}$-band microwave frequency. The study clearly demonstrated that for the ITU parabola fitting method there is wide variation in the radius of curvature due to the frequency.

\section{REFERENCES}

[1] Zheng, L., Lu, N., \& Cai, L. (2013). Reliable Wireless Communication Networks for Demand Response Control. IEEE Trans. Smart Grid, 4(1), 133-140.

[2] Akyol, B. A., Kirkham, H., Clements, S. L., \& Hadley, M. D. (2010). A survey of wireless communications for the electric power system (No. PNNL-19084). Pacific Northwest National Lab.(PNNL), Richland, WA (United States).

[3] Omogbadegun, Z. O., \& Ayo, C. K. (2007). Impact of mobile and wireless technology on healthcare delivery services. 3GSM \& Mobile Computing: An Emerging Growth Engine for National Development, 164-171.

[4] Valenzuela, R. A., \& Kocan, K. F. (2005). Future wireless communications. Bell Labs Technical Journal, 10(2), 1-3.

[5] Niu, Y., Li, Y., Jin, D., Su, L., \& Vasilakos, A. V. (2015). A survey of millimeter wave communications (mmWave) for 5G: opportunities and challenges. Wireless Networks, 21(8), 2657-2676.

[6] Al-Hourani, A., Kandeepan, S., \& Jamalipour, A. (2014, December). Modeling air-to-ground path loss for low altitude platforms in urban environments. In Global Communications Conference (GLOBECOM), 2014 IEEE (pp. 2898-2904). IEEE.

[7] Geng, Y., He, J., \& Pahlavan, K. (2013). Modeling the effect of human body on TOA based indoor human tracking. International Journal of Wireless Information Networks, 20(4), 306-317.

[8] Savazzi, S., Guardiano, S., \& Spagnolini, U. (2013). Wireless sensor network modeling and deployment challenges in oil and gas refinery plants. International journal of distributed sensor networks, 9(3), 383168.
[10] Goldsmith, A. (2005). Wireless communications. Cambridge university press.

[11] Kasampalis, S. (2018). Modelling and coverage improvement of DVB-T networks (Doctoral dissertation, Brunel University London).

[12] Abdulrasool, A. S., Aziz, J. S., \& Abou-Loukh, S. J. (2017). Calculation Algorithm for Diffraction Losses of Multiple Obstacles Based on Epstein-Peterson Approach. International Journal of Antennas and Propagation, 2017.

[13]

[14] Zang, J., \& Wang, X. (2017). Measurements and Modeling of Path Loss over Irregular Terrain for NearGround and Short-Range Communications. Progress In Electromagnetics Research, 57, 55-62.

[15] Cid, E. L. (2017). Lms and h-satcom channels characterization at $x$ and $k u$ bands (Doctoral dissertation, Universidade de Vigo).

[16] Filiposka, S., \& Trajanov, D. (2011). Terrain-aware three-dimensional radio-propagation model extension for NS-2. Simulation, 87(1-2), 7-23.

[17] Kumar, K. A. M. (2011). Significance of Empirical and Physical Propagation Models to Calculate the Excess Path Loss. Journal of Engineering Research and Studies E-ISSN, 976, 7916.

[18] Milanović, J., Rimac-Drlje, S., \& Majerski, I. (2010). Radio wave propagation mechanisms and empirical models for fixed wireless access systems. Tehnički vjesnik, 17(1), 43-53.

[19] Uko, M. C., Udoka, U. E., \& Nkwocha, C. P. (2017). Parametric Analysis of Isolated Doubled Edged Hill Diffraction Loss Based on Rounded Edge Diffraction Loss Method and Different Radius of Curvature Methods. Mathematical and Software Engineering, 3(2), 217-225.

[20] Poisel, R. (2011). Modern Communications Jamming: Principles and Techniques. Artech House.

[21] Vélez, M. M., Angueira, P., De la Vega, D., Arrinda, A., Ordiales, J. L., \& Vicente, A. S. (2000). Ground Profile Analysis Algorithm To Improve Multiple Diffraction Loss Estimation. In Proceedings Of The International Symposium On Antennas And Propagation Japan (Vol. 3, pp. 1347-1350).

[22] Series, P. (2018 ). Propagation by diffraction. Recommendation ITU-R P.526-14. Available at https://www.itu.int/dms_pubrec/itu-r/rec/p/R-RECP.526-14-201801-I!!PDF-E.pdf. Accessed on November 122018.

[23] Akkasli, C. (2009). Methods for Path loss Prediction. Master thesis at School of Mathematics and Systems Engineering 